\title{
SILÊNCIO
}

\section{Um contraponto entre a norma e a transgressão}

\author{
SILENCE \\ A counterpoint between the norm and transgression
}

Beth Lopes ${ }^{1}$

Resumo

O texto fala sobre o processo de criação do espetáculo SILÊNCIO, montado em 1997 e remontado em 2011. O espetáculo é uma adaptação do texto Self-Accusation, do escritor austríaco Peter Handke, com direção de Beth Lopes, a autora desse artigo, e dos atores Yedda Chaves e Matteo Bonfitto, também co-tradutor da peça. A desconstrução de Derrida serve de operador para a desmontagem do espetáculo transposta para uma escrita performática que reúne o material arquivado pela autora-diretora em seus cadernos e em registros fotográficos.

Palavras-chave: Encenação, processo de criação, performance, desmontagem de espetáculo, ator

\section{Resumen}

El texto habla sobre el proceso de creación del espectáculo SILENCE, escenificado en 1997 y reescenificado en 2011. El espectáculo es una adaptación del texto Self-Accusation, del escritor austriaco Peter Handke, dirigido por Beth Lopes, la autora del artículo, y con los actores Yedda Chaves y Matteo Bonfitto, también, co-traductor de la pieza. La deconstrucción de Derrida sirve como operador para la desmontage de escena transpuesto a una escritura performativa a que reúne el material archivado por la autora-directora en sus cuadernos y registros fotográficos.

Palabras clave: Escenificación, proceso de creación, performane, desmontaje de escenas, el actor

\section{Abstract}

The text talks about the process of creating of the spetacle SILENCE, staged in 1997 and reenacted in 2011. The spectacle is an adaptation of the text Self-Accusation, of the Austrian writer Peter Handke, directed by Beth Lopes, with the performers Yedda Chaves and Matteo Bonfitto, also, cotranslator of the piece. The Derrida's deconstruction serves as operator to dismantling the spectacle transposed into a performance writing that gathers the material filed by the authordirector in her notebooks and photographic records.

Keywords: Stage, process of creation, performance, disassembly of stage, actor

\footnotetext{
${ }^{1}$ Programa de Pós-Graduação em Artes Cênicas. Escola de Comunicação e Artes. Universidade de São Paulo
} 
$\mathbf{S}$

I

$\mathbf{L}$

$\hat{\mathbf{E}}$

$\mathbf{N}$

C

I

$\mathbf{O}$

_ entre a norma e a transgressão

$\mathbf{S}$

I

$\mathbf{L}$

$\mathbf{E}$

$\mathbf{N}$

C

$\mathbf{E}$

between norm and transgression 
São Paulo, junho de 2014.

Uma carta de amor para uma amiga

Queridíssima,

Queria, com estes dedos que escrevem estas impressões, que eu pudesse tocar e eternizar a nossa inestimável amizade e as sutilezas de nossas experiências teatrais. Queria que estes arquivos da memória pudessem ser um presente, principalmente, aos que fizeram parte desta história de vida, mas também àqueles que não fizeram parte. Para que com estes documentos, os leitores interessados possam entrever um modo de existência que se constitui a partir de um olhar estético particular para a vida, do mesmo modo que o fazer criativo repleto da presença de vida. Foco na vida, porque ela passa rapidamente e deixa em quem vai depois um sentimento implacável: a falta do outro. Queria poder juntar todos os fragmentos da memória e fazer um presente feito um colar de pérolas. Cada uma conteria em seu micro-universo as alegrias, as decepções, as conquistas, os desafios, os obstáculos, as diferenças, os conhecimentos, presos entre si em uma sequência desorganizada, as tantas qualidades e problemas que dividimos no entrecruzamento de nossos destinos. Queria só poder conduzir/escolher novamente, os movimentos de suas pernas, de seus braços, de sua cabeça, de seus olhos, de seus lábios, de sua voz. Tendo a certeza que em seus gestos-respostas você me surpreenderia com torções e contrastes delicados que dariam à sua presença uma extensa tessitura que iria do trágico ao cômico. Queria que, sem querer, pudesse arrebentar o colar e abrir os pedacinhos para revelar o que os corpos dos atores/performer desse processo de criação deixavam, nos detalhes, esconder. Talvez eu pudesse falar sobre o presente do processo de criação, que já se tornou passado, que meus dedos tornariam velhos os novos momentos, instaurando o presente, novamente, para o nosso leitor. Para acabar, tenho que dizer que quando lembro de tudo isso, tenho vontade de celebrar:

Touché, Yedda! 
Entre os espetáculos que dirigi - Silêncio ${ }^{2}$ - considero um processo que situo entre a experiência e o saber. Um processo de trabalho com o qual sempre desejo repensar. Hoje, com esta escrita, tenho uma crença: na verdade e na potência da experiência. E a certeza que este saber se transformou e se revigorou. Por esta razão, me proponho a submeter o processo a um questionamento desconstrutivo, como indica Jaques Derrida, "tratando de desfazer,

decompor,

des-sedimentar estruturas (todo tipo de estrutura...).

Como explica Derrida, o sentido do uso da palavra "desconstrução" não é uma operação negativa, porque "mais que destruir era preciso assim mesmo como se havia construído um "conjunto" e, para isso, era preciso reconstruí-lo.” (DERRIDA, 1997, p. 3-4)

Este texto é, portanto, uma proposta de processo revisitado, à luz da desmontagem de cenas examinada por Ileana Diéguez, o qual se organiza em torno do processo de criação de Silêncio, de 1997. O texto é em si, um outro processo, pois para isso precisei revisar, revistar o projeto do passado, além de, transpor para uma outra escritura, a da performatividade da escrita, considerandose o espetáculo como uma outra escritura. Preciso reforçar não só o sentido artístico, mas o pedagógico embutido neste ato, o da encenação, já que ao abrir os meus cadernos, minhas anotações, meus rabiscos, escritos, críticas, fotos, lembranças, eu tento revelar "as estratégias performativas de uma pesquisa e criação de um espetáculo" - diz Diéguez, de uma prática préexistente e modelar em uma outra prática, a da escrita, em suas lacunas, hiatos, imperfeições semelhantes ao da própria vida. Querendo sempre que a revelação desta prática toque o inexorável.

Porque redesconstruir um processo de criação-de Silêncio, montagem de 1997, mesmo-que remontado, em-2011? Respondo-logo, sem-certezas: Talvez porque, o-espetáculo, o-tema, 0 texto, o trabalho dos atores, o modo de fazer, possa ser bem mais compreendido hoje do que antes..

${ }^{2}$ Silêncio é o nome dado, por mim e os atores Matteo Bonfitto e Yedda Chaves, à versão que montamos, em 1994 e remontamos em 2011, de Self-accusation, de Peter Handke. 
Peço que o leitor, agora, faça uma pausa e feche os olhos, permanecendo assim por alguns

instantes antes de prosseguir.

Procure lembrar de algum processo de criação

e qual é a primeira imagem que vem à sua memória?

pronto.

foi mais ou menos assim que eu comecei. Um dia, durante os ensaios, eu deixei uma tarefa para os atores: Criar uma versão deles de um fragmento do texto. Na verdade foi uma estratégia que sempre uso quando preciso conhecer o trabalho dos atores. Como eles resolveriam a cena era o que menos me interessava, mas o modo como eles iriam atuar. Dei uns dias para eles prepararem e quando chegou o dia percebi que eles fizeram daquele desafio um ritual. Tinham montado uma cena de amor e ódio entre dois amantes, com começo, meio e fim. Tenho que confessar que tive a impressão de que era um pouco a memória vivida dos dois que, parceiros eternos, tinham vivido esta relação em suas últimas conseqüências, a do amor. A despeito do realismo que achei que eles deram à cena, eu saí satisfeita, eu estava diante de dois monstros-atores, eles tinham uma marca registrada, a de fazer do momento da atuação um relâmpago de vida, intenso, sem limites, desejante, tocante. Eu fui tomada de surpresa, porque, eu não pressentia esta potência em vida, Yedda era feita só de delicadezas e o Matteo tinha os movimentos e um comportamento, eu diria, quase formais. Eles se transformaram, tornaram-se animalescos. Gostei. Essa primeira impressão permaneceu em minhas orientações para o processo, mas devíamos tirar as marcas de representação e buscar dar ao espectador apenas pistas de uma história pela movimentação e gestualidade deles. Assim, quando ele pensasse que estava reconhecendo uma história, ele seria arrancado da estabilidade do começo-meio-fim, para entender que tais histórias poderiam se passar tanto no micro como no macro-universo da história da cultura contemporânea, a partir do S20, com as grandes transformações políticas, como o avanço do imperialismo capitalista e de sua burocracia incompetente, por um lado, e as lutas para a conquista da liberdade e direitos iguais, em outro. 


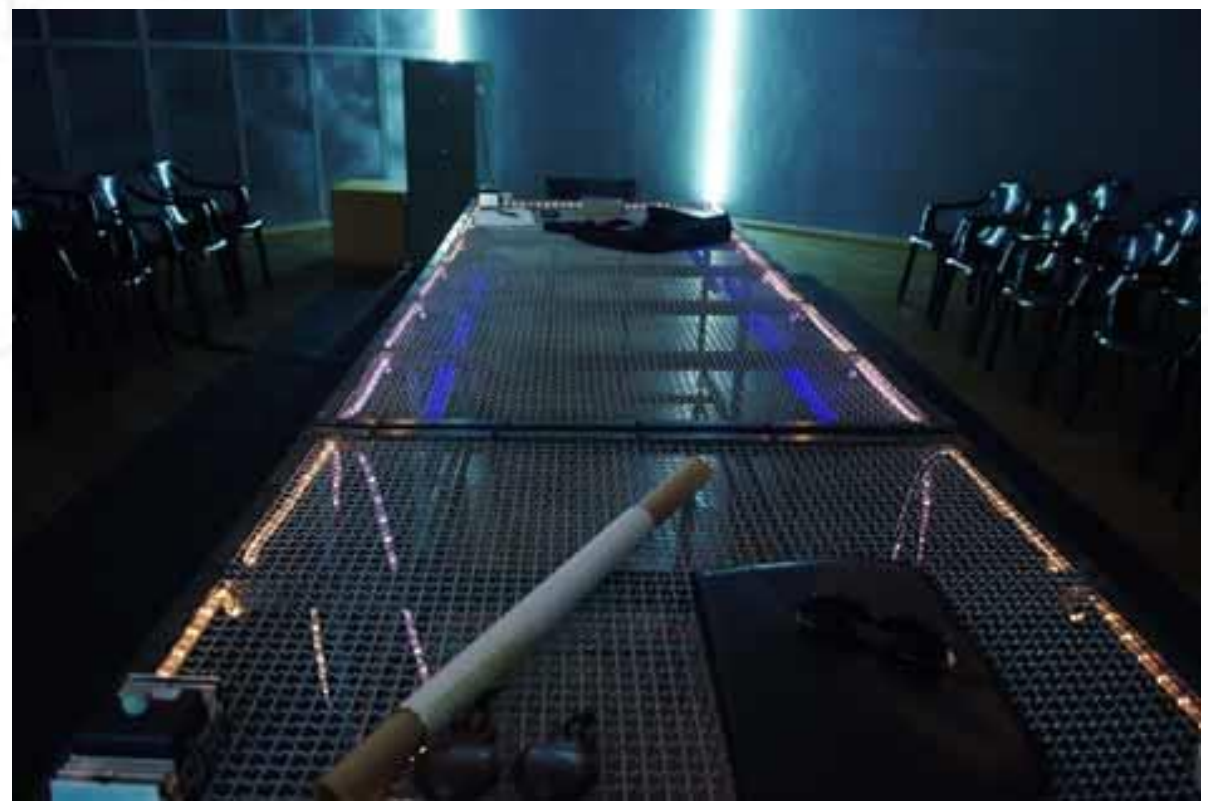

Posso dizer que, como encenadora, fui sempre motivada por investigar os caminhos com que se compõe um espetáculo para pensar em seu conjunto resultante, mas, paradoxalmente, isto sempre me levou

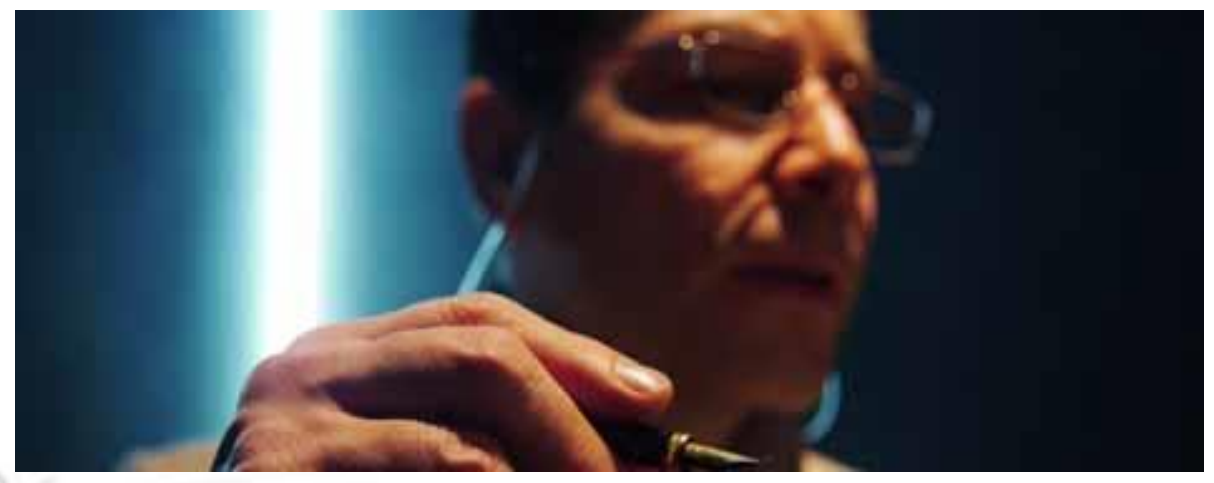
ao extremo oposto, o da desconstrução da obra, do texto, da peça, da ideia ou mesmo de um ponto de vista, movida naturalmente por fazer

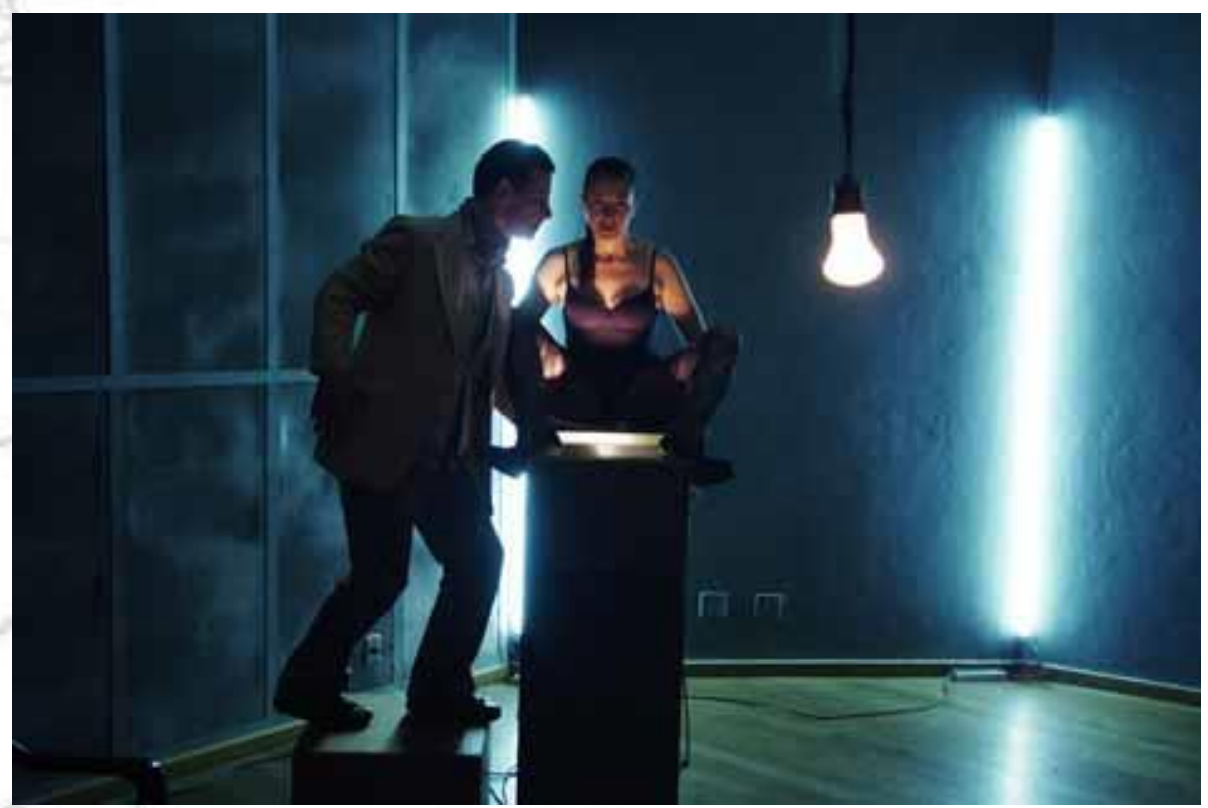
de um processo de criação, uma espécie de experiência única. Não foi diferente no processo de criação de Silêncio, obra encenada em 1997 e reencenada em 2011.

fotos: João Maria 
O ponto central dessa experiência foi, com certeza, o encontro com os dois atores com quem eu podia compartilhar conhecimentos e práticas na mesma linha das questões a serem desdobradas pela criação. Com o mesmo interesse pela investigação das genuínas possibilidades da linguagem teatral, pelo treinamento, pela ação física, pela composição, pela instauração da ação, de algum modo, 'viva', no espetáculo. Na busca pela força da teatralidade da vida, na cena. Nos unimos pela paixão da artesania que era o que nos interessava na arte do ator. Cientes de que encontrar um modo específico de fazer este espetáculo, consistia em imperfeições e gestos inacabados como são as emoções do ser humano.

\section{SHÊNCIOÉ ONOME DADO AO ESPETÁCULOA PARTIR DO TEXTO SELF ACCUSATHONDE PETER HANDKE, de 1966, QUE \\ ENCONTROUNESTA DOMINAÇÃOO \\ SENTIDODA SUA \\ FATURA, A CONSTITUIÇÃO DE UMCAMINHOQUE, SINTETICAMENTE, DESCREVE $\theta$ PERCURSODA PALAVRA AO ESVAZIAMENTODE SENTIDOS, QUE ENVOLVE UMA LINHA QUE VAIDA PROFUSÃO RUIDOSA DOS SENTIDOS AO MAIS COMPLETO SIÊNCIO.}

Self Accusation foi criada para rádio e foi gravada, em 1968, pela BBC Third Programme. Pode ser ouvida no https://www.youtube.com/ watch? $v=a 8 Z i 0 X U C e O M$
Um outro forte elemento foi o texto de Handke (2000) que caiu em nossas mãos como um desafio. A primeira impressão que me atraiu foi o formato anti-teatral, por trazer possibilidades de multiplicação das autorias criativas. E uma sensação de que tem algo no texto que mistura poesia com violência. Apesar da maior dificuldade por não se ter personagens estruturados, mas uma 'voz' que fala saída não se sabe de onde, nem de quem, penso em ecos para essa 'voz', distribuindo o texto entre os dois sem querer estabelecer nenhum critério que justifique um ponto de vista ou dê um entendimento realista ao texto. Distribuo quase aleatoriamente entre os dois atores, às vezes seguindo uma divisão meramente intuitiva, com a mesma quantidade de texto para cada um, sem tornar um mais importante que o outro. Centrava a ideia dos ecos de vozes de alguém, ora enfatizando a noção de voz única ora também de múltiplas vozes que às, vezes, poderiam configurar, até mesmo, a clássica contracenação entre dois personagens.

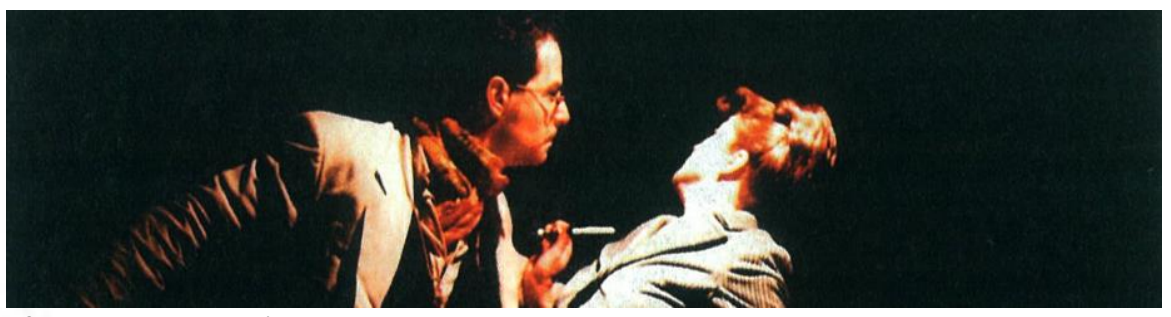

foto: João Maria 
Speak in - não são peças, mas endereçamentos para a platéia

Muitas palavras, Um longo poema

Os atuantes não tem ação. Não-representação sem imagens.

Composição de palavras encantatórias

Jogos de linguagem

Sem diáloge

Sem trama

Sem persenagem,

Material da linguagem cotidiana:

máximas, slogans, propagandas, congratulações.

Handke constrói uma espécie de environmental art (arte ambiental)

A estrutura dramática mostra a regimentação do indivíduo

pela percepção da linguagem condicionada.

Ele recicla formas populares de uma arte radical 
OS EXPERIMENTOS DO DRAMATURDO PETER HANDKE (1942) PODEM SER

RELACIONADOS DE MODO DIFERENTE COM MANIFESTAÇÕES COMO O HAPPENING.

LONGE DE NEGAR O TEXTO ESTRITO, HANDKE O PRIVILEGIA. SEGUNDO O FILÓSOFO LUDWIG WITTGENSTEIN (1889-1952) PEÇAS POR ELE PRODUZIDAS FORAM AS VEZES CARACTERIZADAS COMO ALUSÕES A ARTISTAS COMO CAGE EM SEU REPÚDIO DA ILUSÃO E DA EMPATIA, E EM SUA INSISTÊNCIA NA REALIDADE IMEDIATA. A CONSCIÊNCIA EXPERIMENTAL BUSCADA POR OUTROS EM IMAGEM, HANDKE BUSCA-A EM PALAVRAS. (CARLSON, 1997, p. 447)

A ideia do Silêncio foi a de 'por em jogo', como diz Patrice Pavis (2010, p. XXIV), com relação à encenação contemporânea.

Acho uma expressão adequada por referir-se ao jogo que em sua natureza abre-se às possibilidades de escolhas, de caminhos, de abordagens de um texto, de compartilhamento das autorias, que se estendem, neste caso, para além do autor do texto, para os atores, diretora, design de luz e som.

Algo que surge desta convivência. 


\section{Treinamento e a relação com a cena}

Em meu trabalho como encenadora, como professora ou como provocadora na criação de um espetáculo que se inicia tão logo se entra na sala de ensaio com os atores, lanço mão do jogo dos opostos como uma forma de atravessamento das inúmeras camadas de significação que se compõe um projeto artístico. Os oximoros, destacados da pesquisa com o corpo e o jogo grotesco do bufão ${ }^{3}$ servem como uma espécie de pólo de tensões sobre o qual se constroem os diferentes discursos.

Sigo buscando, por meio de

experimentações

vocais e corporais, no embalo da fluência monológica do texto, mas orquestrada pelas diferentes respirações, volumes, intensidades e ritmos buscados junto aos atores. Com a experimentação de vozes e gestos para elas surgem imagens cuja potência remetem à figuras ou personas. Destas personificações que ora ostentam poder ora fragilidade, surge a ideia de um encontro:

\footnotetext{
${ }^{3}$ Ver em Lopes, 2001, USP.
}

\section{entre duas pessoas}

entre duas potências,

entre dois países,

entre dois governantes,

entre dois amantes,

uma disputa.

Situo estas vozes e figuras nas pontas de uma enorme mesa de reuniões que é onde tudo começa. Ao redor desta mesa os dois:

\section{Se conhecem-disputam-discutem}

\section{aproximam-se}

\section{descobrem-se-amam-se-odeiam-se.}

Falam tanto e a tal ponto que no fim acabam por calar-se, restando apenas os vestígios daquilo que vieram fazer ali, com aquelas palavras, naquele palco, com a mais pura teatralidade, resta a clarificação de que a linguagem é incapaz de dizer algo sobre a sua experiência, sobre si mesma, restando no lugar apenas o silêncio. 
eu comecei a me mexer/

eu mexi certas partes do meu corpo/

\section{Oposições}

eu articulei meu corpo/

eu andei por lugares/

eu me deixei manipular/

eu andei para lá e para cá/

eu forcei a me mexer/

eu mal entendi/

eu descobri que eu existia/

eu prendi atenção sobre mim/

eu criei/eu comecei a falar/

eu entendi os ruídos/

eu reconheci os barulhos/

eu manifestei ruidosamente/

eu deixei de fazer sons/

eu mudei/

eu pude falar/eu pude calar/

eu vi aquilo que revi/

eu tomei consciênciea silêncio e grito

falar e calar-se

fazer e parar

desejar e conter-se

viver e morrer

nascer e matar
Wittgenstein propôs um pensamento inédito até aquele momento: se não se pode falar algo, porque não há meios, então é melhor se calar, um pensador que investiga a linguagem deve gostar e incentivar a opção pelo silêncio 

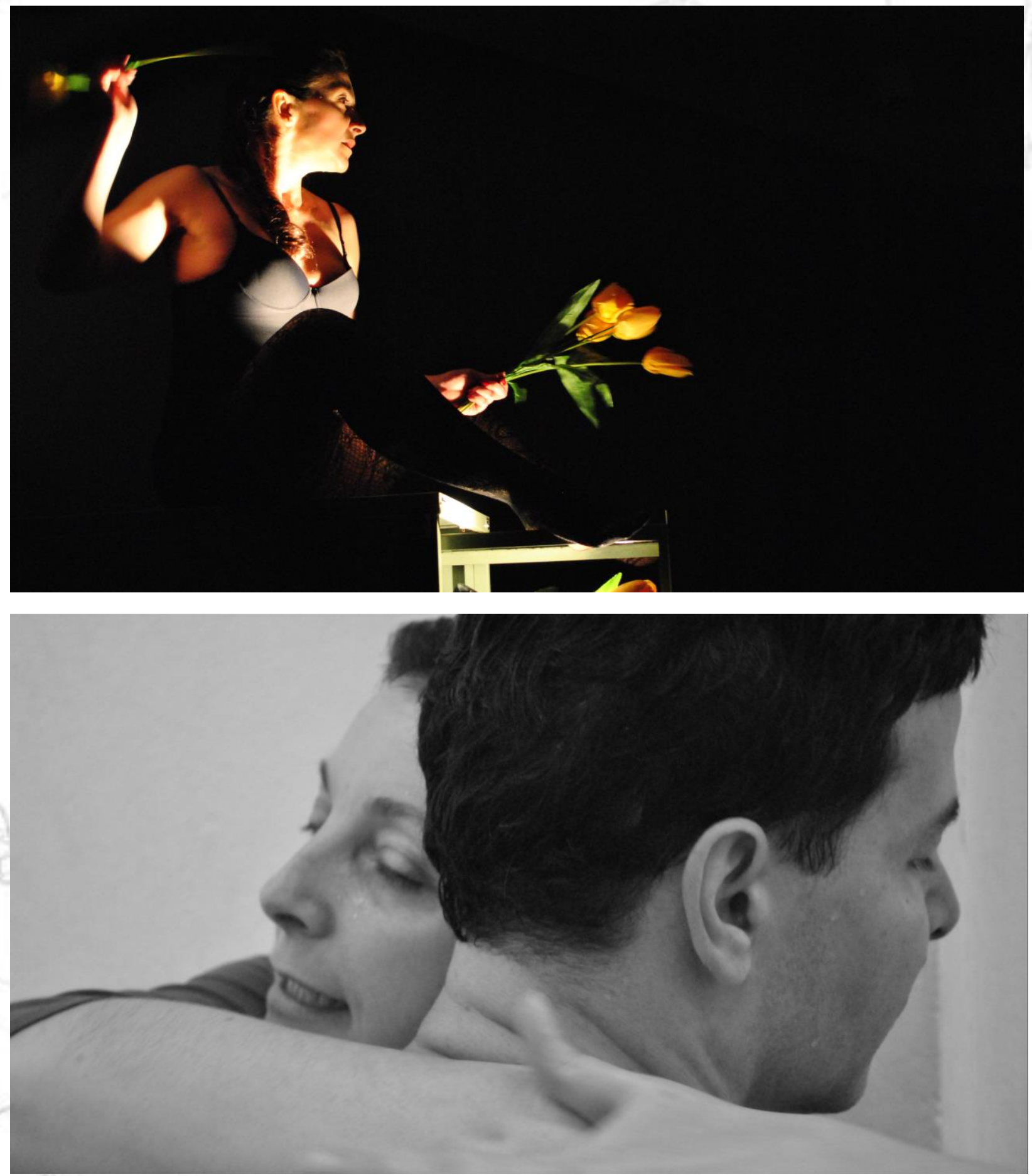

fotos: João Maria 


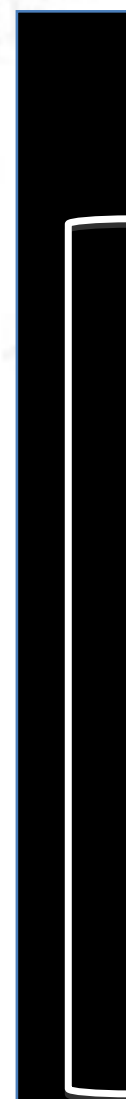

SILÊNCIO COMPOSIÇÕES

UM MONÓLOGO À DOIS

(MATTEO E YEDDA)

Elementos da composição do Matteo

1.Demônio/anjo/reação

2. Mãos de demônio com vozes de anjo/ mão de anjo com voz de demônio

3. Sons:

Canto/risada/grito/modificações/fluidez

4. Energias: cantor de ópera, Popeie, Buster Keaton,

Pato Donald, King Kong, Tarzan, Índio, galã, Woody Allen.

5. Trabalho com os pés, modos de caminhar.

ON D E E C OMO

A C O N T E C EM

ESTES JOGOS DE

P A L A V R A S?

olhar

olhar

pensamento

Elementos da composição da Yedda

1.Demônio/anjo/reação

histórias

2. Mãos de demônio com vozes de anjo/ mão de anjo com voz de demônio

ação

3. Sons: voz de anjo, voz de demônio, falar em russo, contos de fada, cantar, gritar, agudos e graves.

4. Energias: Caipira paulista, camponesa italiana, agente russa, baliza de banda escolar, carola, dançarina de katakali.

queda no vazio

ilusão

descarga elétrica 
destruição

transitoriedade

uma reunião

um encontro entre desconhecidos

em algum lugar

uma disputa - um encontro - confissões

duas pessoas, duas potências, dois poderes

coragem, medo, arrogância, inocência

nas extremidades de uma mesa de reuniões

OUTRAS COMPOSIÇÕES

O QUE VOCÊ AINDA NÃO SABE?

O QUE VOCÊ AINDA NÃO APRENDEU?

DO QUE VOCÊ TEM MEDO?

Levantadas as partituras físicas e vocais, iniciou-se uma fase delicada de articulação, de entrelaçamento desses materiais. O objetivo não era fechar possibilidades, não era produzir articulações fixas, mas sim identificar, reconhecer a existência de "nós expressivos". Chamo de "nós expressivo" qualidades expressivas que, uma vez articuladas entre si, produzem uma espécie de fricção perceptiva que gera ao mesmo tempo possibilidades de desdobramento, produzem uma espécie de crossroad, um campo de latências que pode levar o executor para diferentes direções.

(BONFITTO, 2013, p. 35) 


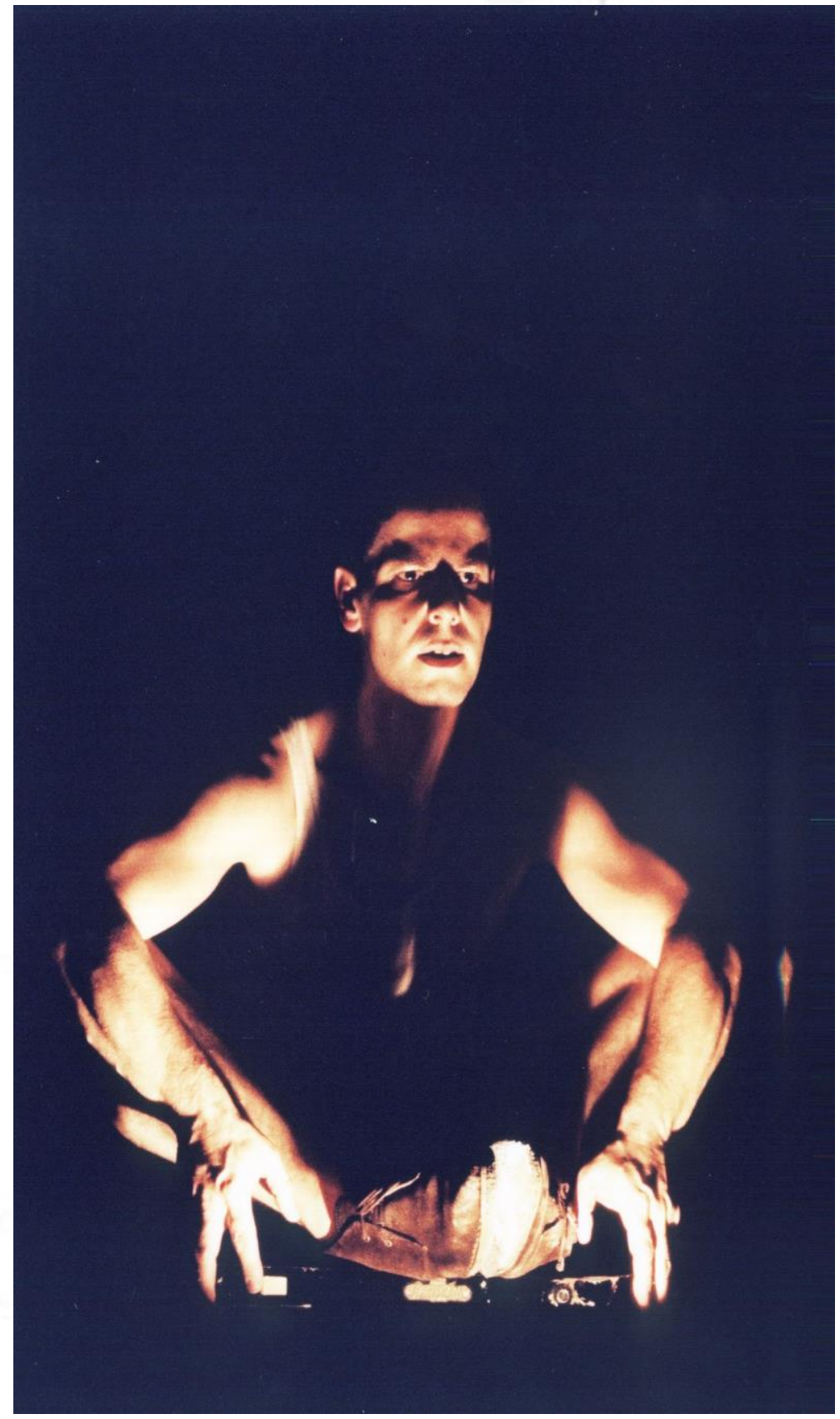


EU NÃO CONSIDEREI MEU MEDO COMO PROVA DE MINHA EXISTÊNCIA EU NÃO CONSIDEREI MEU DESEJO COMO UMA IMORTALIDADE E COMO PROVA DE VIDA APÓS A MORTE EU NÃO CONSIDEREI MINHA REPUGNÂNCIA POR TODAS AS COISAS POR VIR COMO UMA PROVA DO NASCIMENTO APÓS A MORTE EU NÃO CONSIDEREI O PESO DA MINHA DOR EU NÃO SOU O QUE FUI EU JAMAIS SEREI O QUE EU PODERIA SER EU FUI AO TEATRO EU INTERPRETEI ESTA PEÇA EU ESCREVI ESTA PEÇA (HANDKE, 2000)

Dentro do jogo de tensões a ser examinado aqui, entre as dimensões de identidade e alteridade, entre o Eu e o Outro, refletir sobre esse espetáculo representa um estímulo único, pois se por um lado olhar para uma experiência já vivida reforça a dimesão de alteridade, por outro o texto a partir do qual a pesquisa teve início - Self Accusation (Auto-acusação) - apresenta características específicas, dentre elas o fato de todas as frases iniciarem com a palavra "eu", o que gerou inúmeras aberturas e fechamentos, dificuldades e descobertas. (BONFITTO, 2013, p. 32) 
De: bethlopes@usp.br

Para: yeddacarvalho@usp.br

Oi querida,

Por onde você anda? Liguei, mas ninguém atendeu...

Beijo,

Beth

De: yeddacarvalho@usp.br

Para: bethlopes@usp.br

Beth, estou internada em Campinas, assim que puder eu ligo para você.

Um grande obrigada, muitos beijos

Yedda.

Sentados sobre esses arquivos, após um longo e intenso embate, os seres ficcionais lançam flores que se fincam na superfície vazada da mesa, gerando a imagem que fecha o espetáculo: dois pássaros, dois anjos, dois fantasmas diante de um grande jardim ou cemitério. Seus próprios túmulos? (BONFITTO, 2013, p. 38) 


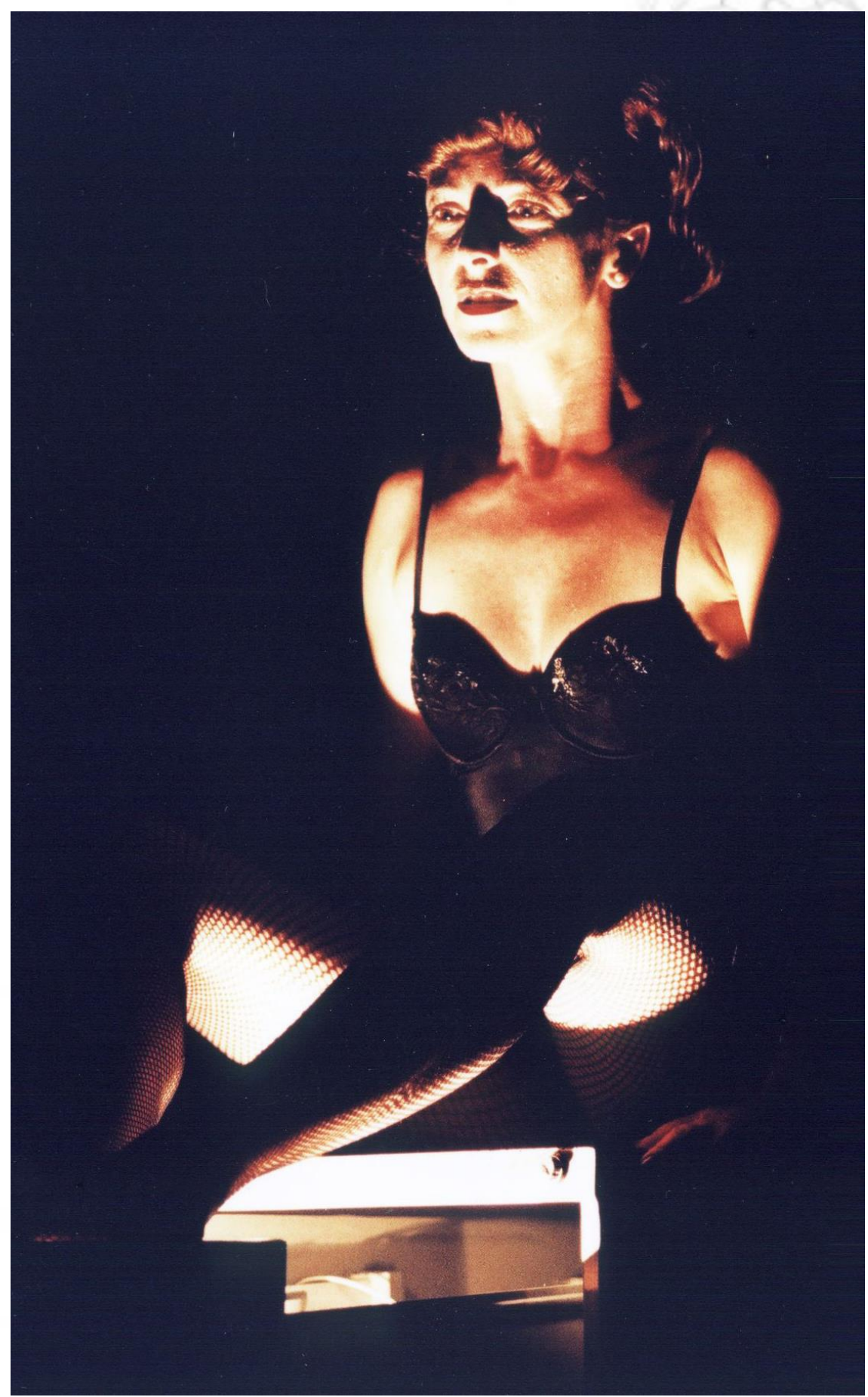

Foto: João Maria

\section{Bibliografia:}

BONFITTO, Matteo. O eu como outro: Algumas incursões no artístico. In: Entre o ator e o performer. São Paulo: Perspectiva, 2013.

O ator-compositor. As Ações Físicas como eixo: de Stanislavski a Barba. São Paulo:

Perspectiva, 2002. 
BUCHHOLZ, Kai. Compreender Wittgenstein. Petrópolis: Editora Vozes, 2008.

CARLSON, Marvin. Teorias do Teatro. Estudo critico dos gregos à atualidade. São Paulo: Editora da UNESP, 1997.

DERRIDA, Jacques. A escritura e a diferença. São Paulo: Perspectiva, 2009.

Carta a un amigo japonês. Traducción de Cristina de Peretti. In El tiempo de una tesis:

Desconstrucción e implicaciones conceptuales. Projecto A Ediciones, Barcelona: 1997, pp 23-27.

Edición digital de Derrida en castellano.

DIÉGUEZ, Ileana. Cenários Liminares. Teatralidades, performances e política. Uberlândia:

EDUFU, 2011.

. Desmontando escenas: Estratégias performativas de investigación y creación. Rio de

Janeiro, 2010. Disponível em: http://tempofestival.com.br/tags/america-latina/

HANDKE, Peter. Self Accusation. BBC Third Programme, 1968. Disponível em:

https://www.youtube.com/watch?v=a8Zi0XUCeOM.

. Self Accusation. Tradução de Alexandre Krug e Matteo Bonfitto, 2000.

LOPES, Elisabeth Silva. Ainda é tempo de bufões. Tese de doutorado defendida em 2001, sob a orientação de Jacó Guinsburg, ECA/USP.

PAVIS, Patrice. A encenação contemporânea. Origens, tendências, perspectivas. São Paulo:

Perspectiva, 2010.

WITTGENSTEIN, Ludwig. Investigações filosóficas. São Paulo: Nova Cultural, 1989. (col. Os pensadores)

Recebido em 10/06/2014

Aprovado em 02/07/2014

Publicado em 31/07/2014 